Metcalfe, G. \& Brown, M. E. (1957). J. gen. Microbiol. 17, 567-572

\title{
Nitrogen Fixation by New Species of Nocardia
}

\author{
By G. METCALFE AND MARGARET E. BROWN* \\ Botany Department, King's College, London, W.C. 2
}

\begin{abstract}
SUMMARY: Two new species of the genus Nocardia (Trev.) have been isolated from the soil of chalk grassland. One of these, Nocardia calcarea n.sp., fixes atmospheric nitrogen in culture in amounts of $2-4.5 \mathrm{mg}$. N/g. glucose, sucrose or mannitol present in the medium. The second species, $N$. cellulans n.sp., decomposes cellulose in culture and fixes atmospheric nitrogen in culture using glucose, sucrose, mannitol and cellulose as carbon source; amounts of $12 \mathrm{mg} . \mathrm{N}$ fixed/g. cellulose decomposed were recorded. The properties of nitrogen fixation and cellulose decomposition have not previously been recorded for this genus. The two organisms are described.
\end{abstract}

The two species of Nocardia to be described were isolated in the course of an examination of the nitrogen-fixing and cellulose-decomposing bacteria in the soil beneath a chalk grassland plant community. As the ability to fix atmospheric nitrogen shown by both these organisms and the ability to decompose cellulose shown by one are attributes not previously recorded for the genus Nocardia, a determinative description of the two organisms (which are regarded as new species) is given. It is proposed to use the name Nocardia cellulans for the cellulose-decomposer and the name $N$. calcarea for the second organism, which as yet has been isolated only from chalk soil.

\section{METHODS}

Isolation of Nocardia calcarea. This organism appeared repeatedly in the course of isolations of species of Azotobacter in liquid enrichment media using chalk soil as inoculum. The 'nitrogen-free' medium had the composition: 3.0 g. $\mathrm{K}_{2} \mathrm{HPO}_{4} ; 1.0$ g. $\mathrm{NaCl} ; 0.01$ g. $\mathrm{MgSO}_{4} .7 \mathrm{H}_{2} \mathrm{O} ; 0.01$ g. $\mathrm{FeCl}_{3} ; 1 \cdot 0$ g. $\mathrm{CaCO}_{3}$; glass-distilled water, 1 l.; 1 p.p.m. $\mathrm{Na}_{2} \mathrm{MoO}_{4} \cdot 2 \mathrm{H}_{2} \mathrm{O} ; 0.3 \%(\mathrm{w} / \mathrm{v})$ sodium benzoate; $\mathrm{pH} \mathrm{7.2.} \mathrm{After} \mathrm{three} \mathrm{successive} \mathrm{transfers} \mathrm{at} 20^{\circ}$ in this medium the enriched cultures were plated on the same medium solidified with washed agar. The colonies of Nocardia were easily differentiated from those of Azotobacter by their pinkish colour. Final isolation was obtained as readily by using mannitol or glucose $(1 \%, \mathrm{w} / \mathrm{v})$ as the carbon supply. Isolation of the organism was also readily achieved by the 'spontaneous culture' method of Winogradsky $(1949$, p. 609) following the addition of sodium acetate to soil samples, also by a modification of his plate insemination method (Winogradsky, 1949, p. 626) in which washed agar was used to solidify the basal medium and butanol added as carbon source.

Isolation of Nocardia cellulans. A silica gel was used impregnated with basal medium (2.5 g. $\mathrm{KNO}_{3} ; 1.0$ g. $\mathrm{K}_{2} \mathrm{HPO}_{4} ; 0 \cdot 1 \mathrm{~g} . \mathrm{CaCl}_{2} ; 0.3 \mathrm{~g} . \mathrm{MgSO}_{4} .7 \mathrm{H}_{2} \mathrm{O}$; $0 \cdot 1$ g. $\mathrm{NaCl} ; 0.01$ g. $\mathrm{FeCl}_{3}$; glass-distilled water, 1 l.; pH 7.0-7.2). Washed

\footnotetext{
* Present address: Rothamsted Experimental Station, Harpenden, Herts.
} 
filter paper placed on the surface of the gel was seeded with minute soil crumbs. After incubating at $\mathbf{2 5}^{\circ}$ for 2-3 days, further plates were inoculated from the areas of decomposition around the crumbs. Mixed cultures were obtained which decomposed the filter paper rapidly and these were plated repeatedly on yeast-extract peptone agar. Between each of these platings the isolates were grown in tubes containing liquid basal medium with strips of washed filter paper. One of the most vigorous cultures so obtained proved to be a nocardia. Pure cultures of this organism grew well in liquid nitrogen-free media and on nitrogen-free agar media. Tests in the filter paper tubes described, with the omission of the $\mathrm{KNO}_{3}$, showed that growth occurred with the simultaneous decomposition of the paper.

Nitrogen determinations. All estimations of nitrogen content were made by the semi-microKjeldahl method described by McKenzie \& Wallace (1954) with mercuric sulphate as catalyst in digestion and added thiosulphate in distillation to break down catalyst complexes. Preliminary experiments showed that in liquid media the two organisms made best growth with mannitol as carbon source. Replicate samples (20 ml.; $0.5 \%$ w/v, mannitol; pH 7.0) of the nitrogen-free medium were inoculated with $1 \mathrm{ml}$. of saline suspension of bacteria; for subsequent use as controls some of the cultures were autoclaved just after inoculation. The cultures were incubated for 14 days at $25^{\circ}$ and determinations of nitrogen content of grown cultures and of the autoclaved controls made. As for the present purposes it was only desired to demonstrate significant changes in nitrogen content, determinations were made on whole cultures which were acidified and evaporated to appropriate volumes on the water bath before digestion. In some experiments cultures and autoclaved controls were aerated continuously during incubation with a slow stream of sterile air freed from ammonia, others were incubated statically. Better growth was obtained in the aerated cultures.

Fixation of nitrogen by Nocardia cellulans with cellulose as carbon source was determined in samples $(20 \mathrm{ml}$; $\mathrm{pH} \mathrm{7.0)}$ of the basal medium without $\mathrm{KNO}_{3}$ and with the addition of a known weight (about $0.4 \mathrm{~g}$.) of washed filter paper. Aeration and the addition of yeast extract (Yeastrel or Marmite) at 1 p.p.m. produced greatly increased growth and cellulose decomposition. Residual cellulose was determined in about half the cultures before nitrogen estimations were made; the method of Fåhraeus (1947) was used with omission of the stage involving washing the residues with ammonia to remove mucilage.

\section{NOCARDIA CALCAREA SP.NOV.}

In 2-day culture, Gram positive and partially acid fast. The morphological cycle on nutrient agar is as follows. After 1-2 days at $25^{\circ}$, mainly short rods $(1.5-2.0 \times 1.0 \mu$.) together with unbranched aseptate filaments up to $10 \mu$. in length and occasional branched filaments. Some filaments show lemon-shaped swellings. After 4 days, mainly short rods showing snapping division typical of corynebacteria; abundant unbranched filaments (5.0-8.0 $\times 1.0 \mu$.) and a few branched filaments and cocci $(1 \cdot 0 \mu$.) also present. After 7 days mainly 
rods; cocci abundant but few filaments. At this stage many rods show the differentiation of a swollen spore-like structure; these are usually formed terminally or subterminally, one per rod. In the filaments they are often formed in chains. Examined in phase-contrast they are hyaline or slightly refractive. Colonies after 14 days consist of short rods, cocci and rods with swollen cells.

On glucose and mannitol agars growth is similar but very long branched filaments $(10-25 \mu$.) are present after 2 days, often with terminal chains of swollen hyaline cells; these filaments usually fragment but a few persist. On yeast-extract peptone medium the cycle is shorter, most of the filaments having fragmented into rods and cocci after 3 days. On sucrose agar, filaments are rare and short rods and cocci are the predominant forms throughout. Occasional lemon-shaped cells are formed on all media.

Litmus milk. Heavy growth, turned alkaline, no peptonization.

Gelatin stab. Beaded growth at top of stab, no liquefaction.

Starch agar. Slight growth, no hydrolysis detectable.

Nitrate peptone broth. Heavy uniform growth, nitrite produced.

Carbohydrate metabolism. In basal salts medium with $\mathrm{NH}_{4} \mathbf{H}_{2} \mathbf{P O}_{4}$ and bromcresol purple, heavy growth with glucose and sucrose; acid produced. Growth good with maltose, poor with lactose.

Paraffin utilization. Growth heavy in basal salts medium with $\mathrm{NH}_{4} \mathrm{H}_{2} \mathrm{PO}_{4}$ and flakes of paraffin wax.

Colonies on agar media. Circular, raised, soft, without aerial mycelium, pink or cream with distinct pink tinge when small, never brightly coloured.

\section{NOCARDIA CELLULANS SP.NOV.}

In 2-day culture, Gram positive and partially acid fast. The morphological cycle on nutrient agar is as follows. After 2 days' incubation at $25^{\circ}$ the growth consists of branching aseptate filaments, $30-40 \mu$. in length, often with swellings at intervals; shorter filaments are present but few are less than $7 \cdot 0 \mu$. in length. About the 4th day fragmentation commences and the number of short rods $(\mathbf{1 \cdot 5 - 2 \cdot 0} \times \mathbf{1 \cdot 0} \mu$.) increases rapidly. Branched filaments (up to $10 \mu$. in length) are present until the 10th day or later. Hyaline sporelike structures are produced from the 7th day as slight terminal swellings on the filaments. After 28 days the colonies consist of very short rods, cocci and spore-like cells.

The morphological cycle on yeast-extract peptone agar is very similar. On glucose agar the filaments fragment less rapidly and are occasionally found after 28 days. Numerous $Y$-forms are found in older cultures. On sucrose agar the filaments seldom exceed $14 \mu$. in length. In cellulose tubes after 6 days there are long $(20-30 \mu$.) branched and unbranched filaments, many with terminal swellings. Fragmentation is rapid and short rods and cocci predominate during the stage of active cellulose decomposition. Old cultures are composed almost entirely of cocci.

Litmus milk. Acid and curd are produced. 
Gelatin stab. Beaded growth at top of stab; no liquefaction.

Starch agar. Starch is not hydrolysed.

Nitrate peptone broth. Heavy, uniform growth; nitrite produced.

Carbohydrate metabolism. In basal salts medium with $\mathrm{NH}_{4} \mathrm{H}_{2} \mathrm{PO}_{4}$ and bromcresol purple, heavy growth with glucose, sucrose and maltose; acid produced.

Paraffin utilization. Growth is heavy in basal salts medium with $\mathrm{NH}_{4} \mathrm{H}_{2} \mathrm{PO}_{4}$ and flakes of paraffin wax if trace of yeast-extract added; no growth without yeast-extract.

Colonies on agar media. Entire, raised, soft, without aerial mycelium, cream in colour on most media but characteristically bright yellow on yeast-extract peptone agar.

\section{NITROGEN FIXATION}

Typical values for nitrogen fixation under the different conditions used are shown in Table 1. There were differences in the degree of fixation and in the utilization of the mannitol between replicate cultures; the same variation was obtained with Azotobacter sp. under the same conditions. Attempts to estimate residual mannitol in the cultures by the method of Cameron, Ross \& Percival (1948) were abandoned as (due to the apparent production of reducing substances in the medium as by-products) consistency could not be obtained for replicate samples of the same culture. Not all the mannitol available had been used.

\section{Table 1. Typical amounts of nitrogen fixed under} different conditions by certain Nocardia spp.

For comparison, values are given for nitrogen fixation by Azotobacter sp. isolated from chalk soil.

Organism

Nocardia calcarea

N. cellulans

Azotobacter sp.

N. cellulans

\section{Conditions}

Mannitol 0.5\%, still cultures Mannitol 0.5\%, aerated cultures Mannitol 0.5\%, with yeast, aerated Glucose $1.0 \%$, with yeast, aerated Sucrose $1.0 \%$, with yeast, aerated Mannitol 1.0\%, with yeast, aerated Mannitol 1.0\%, aerated cultures

Cellulose, aerated cultures Cellulose, with yeast, aerated
Nitrogen fixed (mg. bacterial-N/g. available substrate)

$$
\begin{aligned}
& 2 \cdot 0-4 \cdot 0 \\
& 3 \cdot 0-4 \cdot 5 \\
& 4 \cdot 0 \\
& 2 \cdot 0 \\
& 2 \cdot 5 \\
& 3 \cdot 0-4 \cdot 0 \\
& 7 \cdot 0-9 \cdot 0
\end{aligned}
$$

(mg. bacterial-N/g. cellulose decomposed)

$5 \cdot 0-9 \cdot 0$ $5 \cdot 0-12 \cdot 0$

Quicker initial growth and the higher values of fixation were obtained by adding yeast-extract (Yeastrel or Marmite) to the medium in a concentration of 1 p.p.m. This beneficial effect of added yeast-extract was especially marked with Nocardia cellulans. The constituent of the extract responsible has not been identified. Neither organism seems to require thiamine or biotin and adding these vitamins to the nitrogen-deficient medium produced no stimulation of growth nor was fixation enhanced. Addition of some of the amino acids which are most abundant in yeast-extracts (Special Report, 1956) and 
of other nitrogenous compounds at concentrations of 1 p.p.m. and 10 p.p.m. of fixed nitrogen appeared to suppress fixation. The compounds tested were glutamic acid, leucine, aspartic acid, $\beta$-alanine, $\mathrm{NH}_{4} \mathrm{H}_{2} \mathrm{PO}_{4}$. At 1 p.p.m. of $\mathrm{N}$ all gave fair growth but with doubtful fixation; at 10 p.p.m. there was heavy growth with all except $\beta$-alanine and no fixation.

Long-period serial transfer and storage on nitrogen-deficient medium results, for both organisms, in a gradual loss of ability to fix nitrogen; this ability is restored by transfer to sterile soil. Serial transfer on media such as yeast-extract peptone results in a very rapid loss of fixing ability and, with Nocardia cellulans, loss of ability to decompose cellulose; passage through sterile soil may or may not restore these properties. Both organisms survive and retain their properties over a period of years in damp or air-dry sterile soil.

\section{DISCUSSION}

In view of the wide variety of bacteria which have now been shown to fix atmospheric nitrogen, it is interesting to find members of the Actinomycetaceae that are able to do so. Jensen (1931) stated that no organism belonging to Group II of his classification (the non-proteolytic, non-diastatic group of Norcadia of Bergey's Manual, 1948) could decompose cellulose; Nocardia cellulans would appear to belong to this group. Many species of Streptomyces can decompose cellulose and Jensen (1940) isolated three species of Corynebacterium with this property; it is therefore not surprising to find a cellulosedecomposing member in the related genus Nocardia. The ability to use cellulose directly as the carbon source for nitrogen fixation is novel, but is consistent with the findings of Jensen \& Swaby (1941) and of Jensen (1941) that Azotobacter spp. and Clostridium butyricum can utilize (in nitrogen fixation) the metabolic products formed during cellulose decomposition by a variety of organisms. The present authors (unpublished work) have found that the products of cellulose decomposition by Nocardia cellulans can thus feed azotobacters during nitrogen fixation.

Nocardia cellulans and $N$. calcarea may be placed in the non-proteolytic, non-diastatic group of nocardias. Within the group, $N$. cellulans resembles $N$. polychromogenes, $N$. opaca and $N$. erythropolis in forming extensive initial mycelium and also forming soft colonies without visible aerial mycelium. It differs from these species in other colony characters, in morphology on nutrient agar, in growth characters and reaction in litmus milk and in producing acid from glucose, sucrose and maltose. Within the group, $N$. calcarea has affinities with $N$. salmonicolor, in that the initial mycelium is usually limited and soon breaks up into rods and cocci, but it differs from this species in colony characters, in morphology on nutrient agar, in growth characters on gelatin and in litmus milk and in producing acid from glucose and sucrose.

Active cultures of Nocardia calcarea and N. cellulans have been deposited in the type-culture collection at the National Collection of Industrial Bacteria, Chemical Research Laboratory, Teddington, Middlesex. 


\section{REFERENCES}

Bergey's Manual of Determinative Bacteriology (1948). Sixth ed. Eds. Breed, R. S., Murray, E. G. D. and Hitchens, A. P. London: Baillière, Tindall and Cox.

Cameron, M. C., Ross, A. G. \& Percrval, E. G. V. (1948). Methods for the routine estimation of mannitol, alginic acid and combined fucose in seaweeds. J. Soc. chem. Ind. 67, 161.

FÅrraeUs, G. (1947). Studies in the cellulose decomposition by Cytophaga. Symb. bot. upsaliens. 9, 2.

JENSEN, H. L. (1931). Contributions to our knowledge of Actinomycetales. II. Proc. Linn. Soc. N.S.W. 56, 345.

Jensen, H. L. (1940). Nitrogen fixation and cellulose decomposition by soil microorganisms. I. Proc. Linn. Soc. N.S.W. 65, 543.

Jensen, H. L. (1941). Nitrogen fixation and cellulose decomposition by soil microorganisms. III. Proc. Linn. Soc. N.S.W. 66, 239.

Jensen, H. L. \& Swaby, R. J. (1941). Nitrogen fixation and cellulose decomposition by soil micro-organisms. II. Proc. Linn. Soc. N.S.W. 66, 89.

MCKenziE, H. A. \& WALlaACE, H. S. (1954). The Kjeldahl determination of nitrogen: a critical study of digestion conditions-temperature, catalyst and oxidising agent. Aust. J. Chem. 7, 55.

Special Report (1956). Constituents of Bacteriological Culture Media. Special Report by the Soc. gen. Microbiol. Cambridge University Press.

Winogradsky, S. (1949). Microbiologie du Sol. Paris: Masson et Cie.

(Received 27 March 1957) 